\title{
Nasal Cavity and Ethmoid Sinus Cancer pT3 TNM Finding v6 and v7
}

National Cancer Institute

\section{Source}

National Cancer Institute. Nasal Cavity and Ethmoid Sinus Cancer pT3 TNM Finding v6

and v7. NCI Thesaurus. Code C65053.

Nasal cavity and ethmoid sinus cancer with tumor invading the medial wall or floor of the orbit, maxillary sinus, palate, or cribriform plate. (from AJCC 6th and 7th Eds.) 